\title{
Las esquinas como elemento importante de la configuración urbana. Caso de estudio: Guadalajara, desde la Colonia hasta la primera mitad del siglo $\mathrm{XX}$
}

\author{
Miguel Ángel Benavides González \\ CUAAD, Universidad de Guadalajara, Guadalajara, México \\ E-mail: m_benaviglez@hotmail.com
}

\begin{abstract}
Resumen. La ciudad es un fenómeno en constante transformación que pasa de formas primitivas a formas más complejas, cuyas diferentes etapas de desarrollo son distinguibles. Las etapas de desarrollo son distinguibles a través de las esquinas. Las esquinas son puntos estratégicos generadores de lenguajes formales, su evolución urbana, estructural y arquitectónica define un desarrollo morfológico distintivo, inclusive entre las ciudades novohispanas que parten de un común denominador.

Las similitudes entre las ciudades novohispanas, basadas en el modelo fundacional español apoyado en la retícula, son evidentes. Sin embargo, cada ciudad sostiene una estrecha relación en cuanto a su crecimiento y desarrollo morfológico con las condiciones particulares, tanto sociales como naturales, del contexto en el que se inscriben, lo que les fue imprimiendo un carácter propio. En el caso de Guadalajara, las barranquitas, el arroyo del Arenal, el ferrocarril y el río San Juan de Dios, figuran como algunos de los factores principales que definieron la configuración de la traza urbana.

Estos factores no sólo concretaron el sentido y la orientación del crecimiento de la ciudad, sino que también definieron la morfología de las manzanas, con cuatro tipologías de esquina sobresalientes: la esquina cuadrangular, la esquina aguda, la esquina ochavada y la esquina radial. Estas esquinas del estrato urbano se materializaron en una de las cinco tipologías arquitectónicas de esquina principales: la esquina con pilastra, la esquina con hornacina, la esquina con balcón corrido, la esquina ochavada y la esquina curva, resultantes del pensamiento humano de un momento especifico.
\end{abstract}

Palabras clave: Esquina, morfología urbana, traza urbana, Guadalajara, patrimonio

\section{Guadalajara a través de sus esquinas. Desde la Colonia hasta la primera mitad del siglo XX}

La ciudad de Guadalajara parte de un común denominador en el sistema fundacional español de las ciudades novohispanas en el Nuevo Mundo, basado en la retícula. Método que, con sus respectivas adecuaciones, pudiera estar inspirado en la práctica que se remonta a épocas muy antiguas, vinculado con el sistema fundacional romano; un modelo cuyo perímetro suele ser cuadrado o rectangular, en el que dos vías forman la base de la estructura viaria: "el decumanus [..] y el cardo, [..] y una serie de calles secundarias que completan el trazado en retícula y forman las manzanas de viviendas denominadas insulae". Este sistema seguramente sienta las bases para la organización parcelaria ortogonal que se implementa en las ciudades coloniales latinoamericanas.

Este factor permitió, en una primera instancia, la configuración de la manzana cuadrangular, ya 
que "la forma más usual para afectar los solares en el siglo XVI y parte del XVII fue cuatro solares por manzana, es decir, cada manzana daba cabida a un promedio de cuatro vecinos" . Lo que generó un desarrollo volumétrico de gran uniformidad. Esta homogeneidad está determinada, en gran medida por la casa colonial arquetípica de Guadalajara con el patio central y alrededor de él los cuartos con varios usos, lo que genera diferentes variantes de ocupación del predio que, sin embargo, conserva una serie de características con una gran similitud volumétrica que las hace fácilmente identificables.

Sin embargo, a pesar de las similitudes basadas en el modelo fundacional español entre las ciudades novohispanas y sus orígenes, el crecimiento y el desarrollo morfológico de cada ciudad sostiene una estrecha relación con las condiciones particulares, tanto sociales como naturales, del propio contexto en el que se inscriben, lo que les fue imprimiendo un carácter propio. De manera que, "la condición de cada ciudad iberoamericana, su formación y transformación específica espaciotemporal, histórica; la sociedad concreta que la produce, aunque se parezca en regiones o países por sus condiciones generales a las de otras ciudades, es, hasta cierto punto distinta. Por eso es importante y aún necesario desentrañarla, conocerla y explicarla".

\section{Las esquinas en la traza urbana de Guadalajara}

En el caso de Guadalajara, México; las barranquitas, el arroyo del Arenal, el ferrocarril y especialmente el río San Juan de Dios, figuran como algunos de los elementos que definieron la configuración de la traza urbana, determinaron el sentido y la orientación del crecimiento de la ciudad, y le confirieron una morfología propia. Su crecimiento se consolidó paulatinamente desde su cuarta y definitiva fundación en 1542 en el Valle de Atemajac, y su traza se mantuvo, hasta cierto punto, congruente con el modelo primigenio a lo largo de cerca de cuatro siglos, pese a las variaciones provocadas por los accidentes topográficos, los cursos de agua y los caminos principales, incluso ya entrado el siglo XX con la incursión de las colonias, término que "alude a las nociones modernizadoras guiadas por el higienismo y la búsqueda de espacios socialmente prestigiosos y funcionalmente homogéneos".

Se puede decir entonces que, la estructura urbana de Guadalajara viene determinada por la presencia de cuatro factores fundamentales: por un lado, la retícula, como un "modelo ordenador del espacio, racional, geométrico, claro y homogéneo", producto del sistema fundacionalespañol.Porotrolado,losaccidentes topográficos, los caminos principales y los cursos de agua, éstos dos últimos que suelen seguir la ruta del menor esfuerzo. Así como, el ferrocarril, que influyó en el desarrollo futuro de la mancha urbana, específicamente hacia el extremo sur de la ciudad. Y, por último, el "espíritu modernizador" del régimen porfirista, específicamente en materia de comunicaciones, infraestructura e intervenciones urbanísticas. Éstas últimas bajo la adopción de algunos preceptos del urbanismo moderno europeo de finales del siglo XIX.

No obstante, estos factores no solo concretaron el sentido y la orientación del crecimiento de la ciudad y la dotaron de un carácter propio, sino que también definieron la configuración morfológica de las manzanas del estrato urbano, con cuatro tipologías de esquina destacables: la esquina cuadrangular, vinculada con el sistema fundacional español basado en la retícula; la esquina aguda, como resultado de la urbanización en zonas con accidentes topográficos, por la penetración de los caminos principales y por la presencia de los cursos de agua dentro de la ciudad, es decir, cuencas formadas por ríos y arroyos de temporal; por otro lado, la esquina ochavada, vinculada con el concepto de modernidad inspirado en algunas normas aplicadas por Ildefonso Cerdà en el ensanche de Barcelona; y finalmente, la esquina radial, producto de la adopción de ciertos preceptos del urbanismo moderno europeo, tales como el plan parisino de Georges-Eugène Haussmann.

\section{Tipologías arquitectónicas de las esquinas}

Las diferentes tipologías de esquina del estrato urbano anteriormente mencionadas, se 
materializaron paulatinamente con la adopción de diferentes lenguajes arquitectónicos, en respuesta a una forma de pensamiento colectivo y a un momento histórico específico, en una dicotomía de espacio-tiempo; con lo que se observan cinco tipologías arquitectónicas de esquina destacables: la esquina con pilastra, la esquina con hornacina, la esquina con balcón corrido, la esquina ochavada y la esquina curva. La esquina con pilastra, vinculada generalmente a factores de carácter estructural, la esquina con hornacina, que se manifiesta inicialmente en los edificios eclesiásticos, la esquina con balcón corrido, cuyas primeras manifestaciones en Guadalajara se remontan hacia finales del siglo XVII y principios del XVIII con el aumento de edificios de dos y tres niveles en la ciudad; la esquina ochavada, muchas de éstas como resultante de la implementación de diferentes intervenciones urbanísticas, principalmente tras incursión del tranvía eléctrico en la ciudad; y finalmente, la esquina curva en las primeras décadas del siglo $\mathrm{XX}$, y que figura como uno de los elementos principales que singularizaron la llegada de la modernidad arquitectónica a Guadalajara.

Así, la esquina con pilastra, sugiere su origen, a partir de la necesidad derivada de las limitaciones de los sistemas constructivos y la naturaleza de los materiales. En la capital tapatía, la pilastra esquinera figura como un elemento bastante utilizado con fines estructurales durante el periodo colonial, al funcionar como receptor de los esfuerzos provocados por los empujes de ambos muros encontrados en la arista. Lo anterior resulta bastante evidente, con las pilastras esquineras facturadas con materiales pétreos, especialmente si se toma en consideración el principal sistema constructivo empleado en la ciudad, basado en el uso del adobe y la madera, utilizado incluso ya entrado el siglo XX. Sin embargo, paulatinamente la esquina con pilastra, además de la función sustentante, adquiere una función simbólica y ornamental, por lo que se observan pilastras esquineras adosadas de sección cuadrangular y pilastras esquineras semi exentas, de sección circular, éstas últimas cada vez de mayores proporciones, más riqueza compositiva $\mathrm{y}$ mejor factura.

Con el paso del tiempo y la evolución de los sistemas constructivos, se fue ampliando el conocimiento en cuanto al empuje de las fuerzas para poder sustentarse, y cada vez resultó menos necesaria la utilización de las columnas y pilastras. Sin embargo, la importancia de la pilastra esquinera como soporte estructural en la vivienda tradicional tapatía y su empleo durante varios siglos es evidente; particularmente en las esquinas de la manzana donde la pilastra juega un papel muy importante. Lo que sugiere que la pilastra esquinera, arquetípica de la arquitectura tradicional tapatía, se revela como una de las primeras soluciones proyectuales de la arquitectura en las esquinas urbanas de Guadalajara, vinculada con una función primordialmente estructural.

Por otro lado, "La sociedad novohispana desarrolló una religiosidad que osciló del paganismo más grosero a las más altas formas de espiritualidad. [... El pensamiento religioso que imperó en la Nueva España que influyó sobremanera en las formas educativas, giró en torno del ordenamiento jerárquico que consideraba a la teología como la cumbre de las otras ciencias". De este modo, el pensamiento ideológico y las costumbres que los españoles introdujeron al territorio conquistado estuvieron fuertemente impregnadas por la religiosidad, incluso en la producción arquitectónica, especialmente en los grandes edificios. $\mathrm{La}$ importancia religiosa se manifestaba en pórticos y balcones, columnas, pilastras, nichos y hornacinas centrales y esquineras con figuras religiosas, con los más altos niveles de expresión. Por lo que en Guadalajara, era común encontrar "en la esquina, la clásica columna con un nicho al nivel de la ventana y una cruz en la parte superior de la cornisa" . Es en este contexto que las expresiones estéticas se materializaron con motivos religiosos no sólo en edificios eclesiásticos, sino que trascendieron a la arquitectura habitacional. Así, en Guadalajara uno de los sitios donde se manifiesta esta tendencia, y que atrae nuestra atención, son las esquinas de manzana, con la implementación de hornacinas esquineras; algunas de gran relevancia y otras de singular diseño. Al respecto, destacan dos edificios religiosos que alojan, sin duda, las hornacinas esquineras más relevantes de la ciudad: se trata del templo de Santa Mónica, uno de los 
edificios más significativos del barroco en la ciudad, cuya hornacina esquinera aloja una escultura de grandes proporciones en la advocación de San Cristóbal y, por otro lado, el templo de Jesús María, ambos del siglo XVIII. Asimismo, se tienen algunos edificios del tipo habitacional con distintas variantes de diseño en sus hornacinas esquineras dentro de los que destacan en particular aquellos cuya datación se centra en el siglo XVIII.

Por otro lado, como ya se ha mencionado, la forma más usual de distribución del espacio en Guadalajara durante el siglo XVI y parte del XVII, estuvo marcada por la división de cuatro solares por manzana predominantemente cuadrangulares. Sin embargo, al crecer la cifra de moradores y por consecuencia encarecerse el terreno, "aparece a fines del siglo XVIII una tendencia a densificar el espacio", de tal manera que, "en el siglo XVIII se fue haciendo más frecuente que en el mismo espacio hubiese seis u ocho, (solares): cuatro en esquina y el resto a media cuadra. De ahí que pronto fueran menos raras las casas en planta alta y cada vez más común el uso de balcones pequeños en el piso superior". Ciertamente, aunque en su traza urbana siguió predominando la característica que le imprimiera desde un principio la retícula; la imagen urbana, por su parte, experimentaría una gran transformación, especialmente en la altura de los edificios y por la incursión de un elemento que hasta entonces se había prescindido, el balcón.

El balcón experimenta en sí mismo un proceso de evolución, los pequeños e individuales balcones ulteriormente se prolongaron desde el eje de una calle hacia el eje de la otra, a través del vértice generado por la esquina, dando lugar al concepto de balcón corrido, en aprovechamiento de las bondades y ventajas que un solar con dos fachadas aporta al propio edificio y a la distribución espacial regida por el patio central. Así, el balcón esquinero o balcón corrido se integra, en algunos casos, a la morfología de la esquina ya existente, con una de las manifestaciones de mayor expresividad arquitectónica en Guadalajara; la esquina compuesta, es decir, la esquina provista de pilastra, hornacina y balcón corrido; elementos que con el tiempo se consolidarían como arquetipos de la vivienda tradicional tapatía. Así, con el balcón corrido la esquina adquiere además de su función estructural y estética una trascendencia social y urbana, pues los balcones, "poseen una gran fuerza comunicativa, con las posibilidades de interlocución entre el dominio del espacio interior y el exterior".

Por otro lado, en los albores del siglo XX, la incorporación de la modernidad arquitectónica en Guadalajara al igual que en otras ciudades se dio por diversas circunstancias: sociales, culturales, políticas, y tecnológicas, principalmente; que impulsaron su desarrollo y crecimiento económico en los últimos años decimonónicos. Un crecimiento que estuvo marcado por grandes acontecimientos que modernizaron la ciudad. Por un lado, el arribo del ferrocarril en 1888, "que significó la ampliación de capacidad para el transporte de materias primas y el proceso de distribución de los productos", y por otro, la puesta en marcha de obras urbanas como: la electrificación, el sistema de alcantarillado, agua potable y pavimentación de calles, que imprimieron un nuevo rostro hacia los inicios del nuevo siglo. Esta nueva estructura permitió la incorporación de sistemas de transporte urbano propios de una capital. Así, "los tranvías de tracción animal se inauguraron el 16 de septiembre de 1882" pero, no fue sino hasta 1900 , cuando algunas empresas de la iniciativa privada se interesaron cada uno y por su cuenta, en la introducción de tranvías eléctricos en la capital jalisciense.

Sin embargo, "los primitivos tranvías [..] fueron trazados sobre inseguros y defectuosos rieles de soleras, con durmientes muchas veces paralelos a la propia vía, que por ello resultaba poco eficaz aún para el lento caminar de aquellos pequeños y ligeros carritos que se arrastraban con todos los azotes e inconvenientes del mal genio que caracterizan a las mulas", de manera que la incorporación de los vagones eléctricos demandó un previo acondicionamiento de las calles, donde además de la construcción de las vías, la instalación de postes y el cableado necesario, se requirieron transformaciones urbanísticas que seguramente trascendieron al ámbito arquitectónico. Lo anterior, aunado a la implementación de nuevos materiales y técnicas constructivas, así como los conceptos de modernidad que estuvieron 
en boga particularmente durante las primeras décadas del siglo XX, marcaron la pauta de una arquitectura novedosa reflejada principalmente en las esquinas, con la incursión de la esquina ochavada, cambiando la fisonomía de la capital tapatía notablemente.

En 1907 el sistema de tranvías eléctricos incursionó en Guadalajara, lo que implicó grandes intervenciones urbanísticas, una de las más sobresalientes se observa en la transformación morfológica de algunas manzanas, a partir de la implementación del ochavo en alguno de sus vértices, así como por el traslado del ingreso principal a la esquina. El traslado del ingreso principal a la esquina significó un cambio trascendental, ya que tradicionalmente y por varios siglos, éste se ubicó en el centro del paramento principal, marcado simétricamente por la hegemonía del patio central; éste hecho resulta de gran importancia, no solo desde la perspectiva de la configuración des espacio habitable pero también en el aspecto social, es decir, en la forma de habitar el espacio. En este mismo contexto, se sabe que en 1903 se ochavaron los edificios de la esquina de la Plaza Mayor, según lo describe Villaseñor y Villaseñor en el tenor siguiente: "en el Mesón particular de los Cañedo [..] la puerta principal era muy ancha y muy alta, estaba en ochavo de la esquina y creo que fue la primera esquina con esta novedad al poner la puerta ahí. Es que traían los productos de su hacienda en carretas, que no podían dar la vuelta y entraban de ese modo en línea recta". Asimismo, fue en la colonia Artesanos, en 1904, que se hicieron entradas especiales en la mitad o en las esquinas de las manzanas a fin de utilizar los corazones de las mismas, seguramente inspirado e incorporando algunos de los preceptos del proyecto del Ensanche de Barcelona de Ildefonso Cerdà de 1860. Estos hechos encaminan a pensar que, tal parece que el giro a $45^{\circ}$ y la esquina ochavada, tanto en la proyección urbana como en la arquitectura sostuvo una relación estrecha con la concepción y asimilación de la modernidad arquitectónica en ese tiempo. De esta manera, la esquina ochavada, figura como una de las variantes arquitectónicas que adquirió la esquina urbana en la capital tapatía profusamente empleada particularmente durante los últimos años del

\section{siglo XIX.}

Por otro lado, los primeros años del siglo XX fueron tan vigorosos y trascendentales para la arquitectura en México como sus movimientos sociales. Un periodo que estuvo inmerso en un sentimiento de nacionalismo y modernidad, con una visión de cambio, pero al mismo tiempo con una fuerte tendencia nacionalista. Los acontecimientos sociales, políticos y culturales que se suscitaron tanto en el plano nacional como internacional, dieron pie a varias formas de entender la modernidad, al respecto el historiador brasileño Hugo Segawa señala a México como "el más vigoroso centro de debates teóricos en Latinoamérica a lo largo del siglo XX" . Un periodo marcado por la experimentación y la búsqueda de la identidad nacional.

Por su parte, respecto a las casas habitación, la búsqueda de una expresión local se dio después de 1920, de manera que la arquitectura producida particularmente durante el periodo de las décadas de los años treinta y cuarenta, estuvo marcada por la búsqueda de la identidad sin dejar de lado las tendencias modernas. Se profundizó en las raíces para producir la imagen identitaria de lo "mexicano". Reflejado en la producción arquitectónica de reconocidos personajes como Rafael Urzúa, Pedro Castellanos, Enrique Ladrón de Guevara, Ignacio Díaz Morales y los hermanos Juan José y Luis Barragán, entre otros. Este grupo de jóvenes ingenieros civiles, muestra de la transición del Regionalismo, fueron incorporando un nuevo estilo con varias influencias de origen.

Estos ingenieros se fueron prendando de una estética donde confluían arroyos formales tan diversos como la arquitectura popular, y la arquitectura mediterránea. Por un lado, los que buscaban una arquitectura enraizada al lugar con un estilo regionalista inspirado en el recuerdo de haciendas austeras jaliscienses y pueblos tradicionales de Jalisco como Concepción de Buenos Aires, Tapalpa y Mazamitla, así como en las ilustraciones del libro de Ferdinand Bac. Por otro lado, los que buscaban extrapolar los nuevos preceptos que se divulgaban a través de las revistas y manifiestos internacionales o, que utilizaban los estilismos propios de la época.

Simultáneamente, también se tiene la 
presencia de "los constructores", muchos de ellos anónimos que van construyendo en silencio una arquitectura especialmente doméstica, muy sensata y habitable sin tantas exigencias estilísticas, con la implementación de nuevos materiales y técnicas constructivas; una arquitectura bajo las influencias de los conceptos de modernidad que estuvieron en boga en Europa en albores del nuevo siglo, como las vanguardias modernas y los manifiestos internacionales, el racionalismo de la Bauhaus o la implementación de alguno de los cinco puntos para una nueva arquitectura propuestos por Le Corbusier.

Es así que en esta etapa de experimentación, se detecta la tendencia por el uso de las formas curvas, máxime en las nuevas propuestas compositivas en las esquinas de manzana, seguramente ligado al proceso de industrialización que trajo consigo la implementación del transporte público, particularmente el sistema de tranvías eléctricos que demandó cambios en la estructura urbana, del cual se ha hablado con anterioridad, así como con los nuevos cánones compositivos propuestos por el movimiento moderno europeo. Por lo tanto, la tendencia por el uso de las formas curvas se ve reflejada en la producción arquitectónica de reconocidos personajes como: Pedro Castellanos, Rafael Urzúa, Eduardo Ladrón de Guevara, Ignacio Díaz Morales e inclusive Juan José y Luis Barragán, seguramente como parte del proceso de experimentación del periodo y de su propia trayectoria profesional.
Este periodo estaría delimitado con la construcción, que hasta el momento se considera como la primera obra residencial de estilo contemporáneo en Guadalajara: la Casa Quiñones, proyectada por Pedro Castellanos, cuyo propietario Fernando Quiñónez Vélez, la mandó construir en 1931. Sin embargo, a ésta se sucedieron innumerables obras de aquellos autores cuyos nombres prevalecen bajo la sombra del anonimato, obras que aún se aprecian en la ciudad y que se produjeron como resultado de la transformación urbano espacial que a su paso trajo consigo la adopción de la modernidad durante la primera mitad del siglo $\mathrm{XX}$, marcada seguramente, por la incursión de las formas curvas, y la esquina como la protagonista de la misma, como una manera de interpretar y asimilar la modernidad.

Como se ha visto, la esquina transita en la historia de la arquitectura de Guadalajara en un proceso que discurre a partir del su uso inicialmente estructural con la incorporación de la pilastra; adquiere una función decorativa y simbólica con la hornacina; y alcanza el aspecto funcional con el balcón corrido y el ingreso principal dispuesto en el ochavo de la

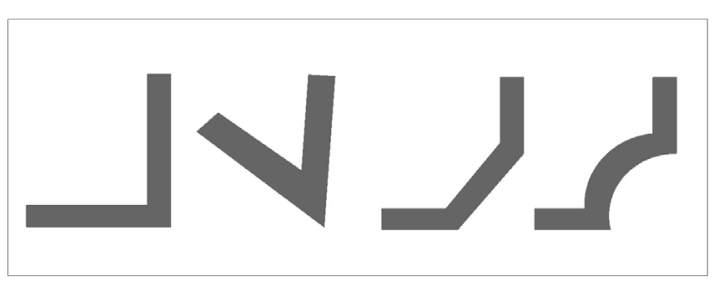

Fig. 1. Tipología de esquinas en la traza urbana de Guadalajara. Esquema de elaboración propia.

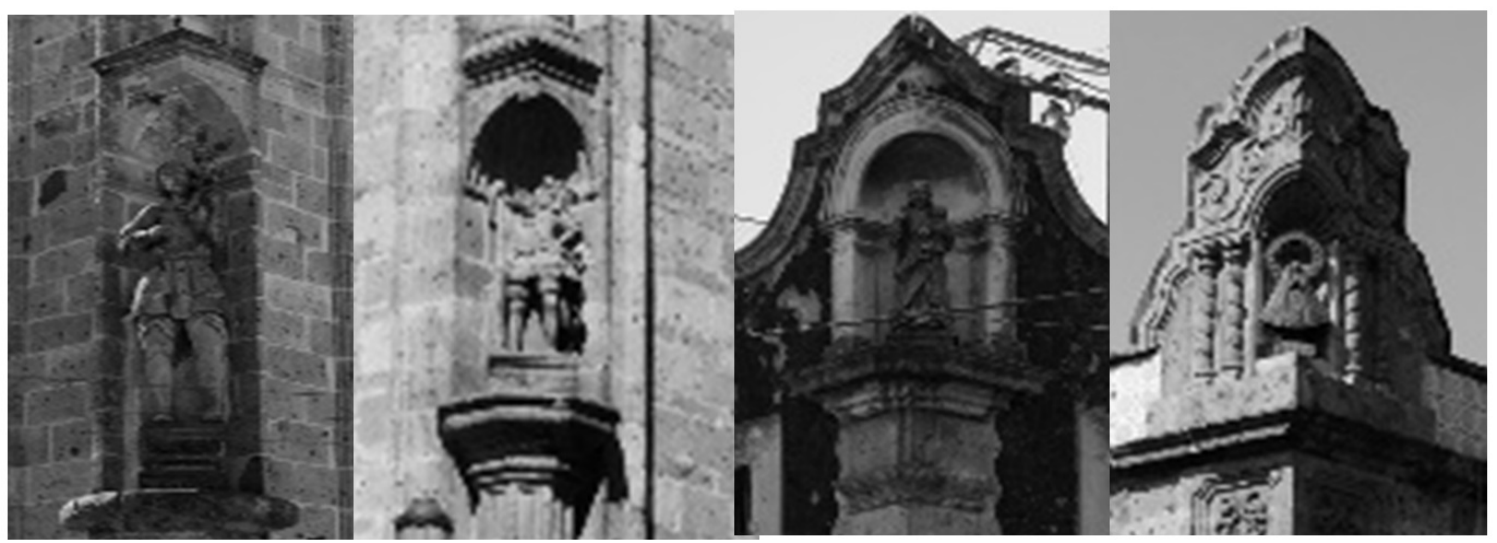

Fig. 2. Ejemplos de hornacinas esquineras en Guadalajara. Fuente: Fotografías, Alonso Escobar. 2017 
manzana; asimismo, la esquina curva figura como uno de los elementos que singularizaron la llegada de la modernidad arquitectónica a Guadalajara. Por lo tanto, se puede aseverar que las esquinas son puntos estratégicos, generadores de lenguajes formales. Son elementos urbano-arquitectónicos que reflejan las distintas etapas de desarrollo de la sociedad que las produce. Las esquinas permiten obtener una lectura histórica de la ciudad, desde una perspectiva diferente.

"Las esquinas son una metáfora de la ciudad porque constituyen una propuesta a partir de la diversidad". Es un elemento identificable, reconocible y utilitario y lo vamos a encontrar presente en cualquier ciudad. Su trascendencia urbana, arquitectónica y estructural, nos conduce a considerar a las esquinas como un componente fundamental a la hora de abordar el estudio del fenómeno urbano. Una pieza escencial que, de alguna manera, podría decirse que viene a complementar la lista de los cinco elementos propuestos por Kevin Lynch en "La imagen de la ciudad". Asimismo, también podría decirse que el planteamiento del estudio sobre cualquier fenómeno urbano no se podría considerar como completo si no es a través de estos seis elementos: las sendas, los nodos, los barrios, los hitos, los bordes y también las esquinas.

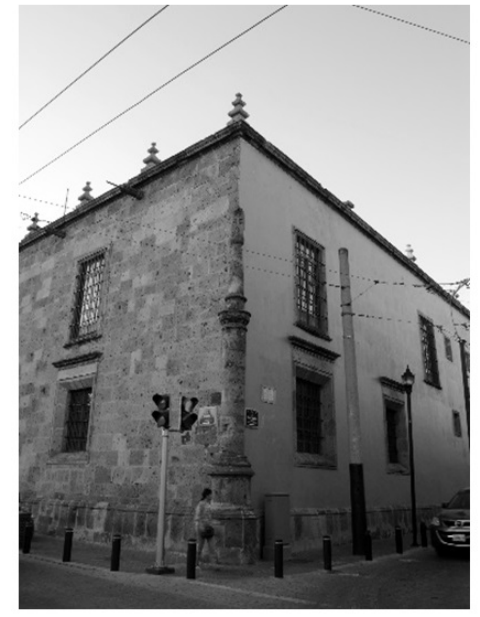

Esquina con pilastra

Barroco. Siglo XVIII

Hidalgo y Pino Suárez

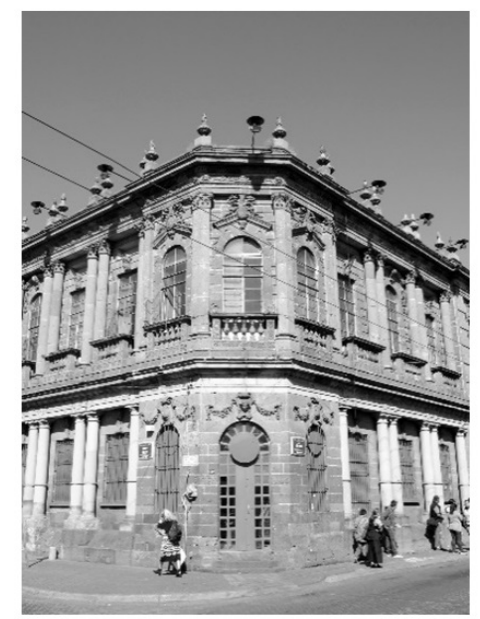

Esquina ochavada

Ecléctico tardío. Siglo XIX

Pedro Moreno y 8 de julio

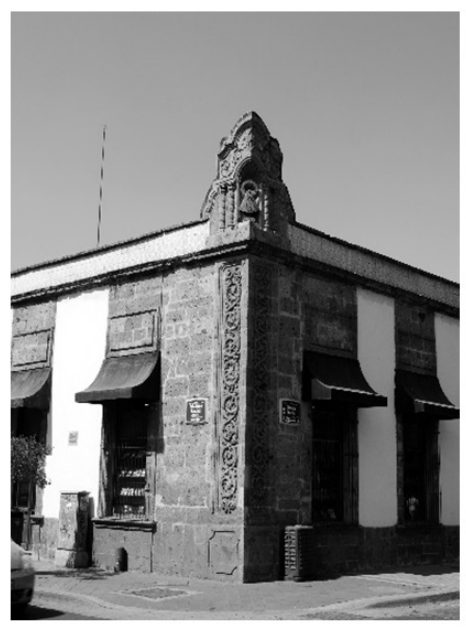

Esquina con pilastra y hornacina Barroco. Siglo XIX

Prisciliano Sánchez y Donato Guerra

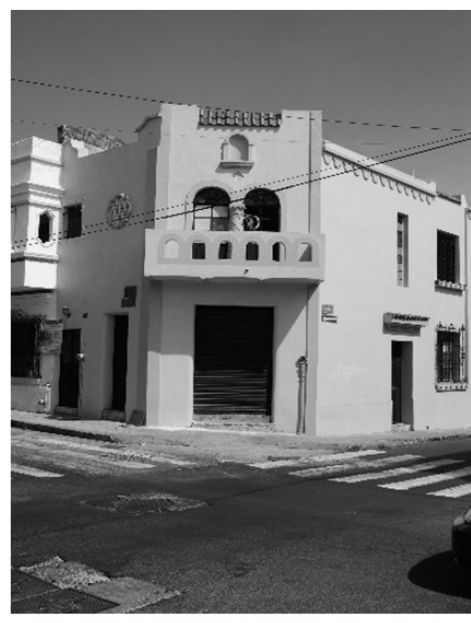

Esquina ochavada

Regionalismo. 1920 - 1940

Garibaldi y Venustiano Carranza

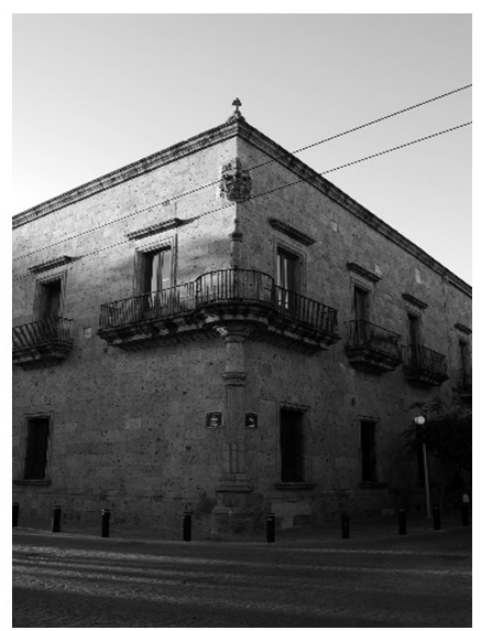

Esquina compuesta Barroco. Siglo XVIII Hidalgo y Belén

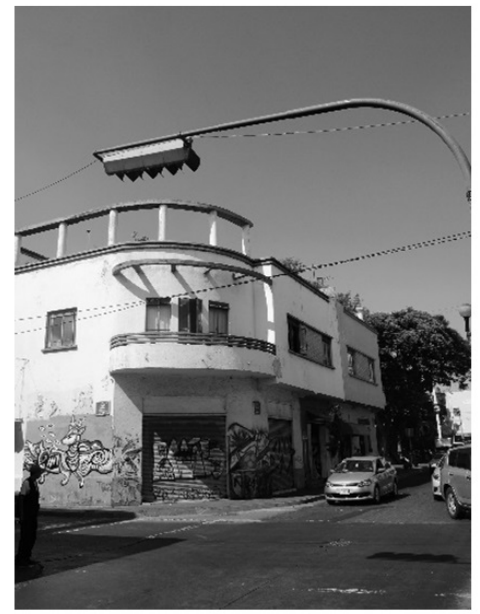

Esquina curva

Funcionalismo. 1940

López Cotilla y 8de julio 


\section{Agradecimientos:}

A la universidad de Guadalajara, mi alma mater, por la oportunidad de crecer profesional y personalmente. Al Centro Universitario de Arte, Arquitectura y Diseño quien a través de la Maestría en Ciencias de la Arquitectura me han dado la oportunidad de crecer.

A mis padres por ser el pilar fundamental de todo lo que soy, en mi educación tanto académica como de la vida, por su invaluable ejemplo, por su incondicional apoyo perfectamente mantenido a través del tiempo, por su amor incondicional, por inculcar en mi valores que me hacen un hombre de bien.

\section{Notas:}

1 López Moreno, Eduardo. 2001. La Cuadrícula en el desarrollo de la ciudad hispanoamericana, Guadalajara, México. Guadalajara: Universidad de Guadalajara, ITESO. 201.

2 Morris, A.E.J. 2015. Historia de la forma urbana, desde sus orígenes hasta la revolución industrial. Barcelona: Gustavo Gili. 59.

3 López Moreno, Eduardo. 2001. La Cuadrícula en el desarrollo de la ciudad hispanoamericana, Guadalajara, México. Guadalajara: Universidad de Guadalajara, ITESO. 202.

4 Vázquez, Daniel. 2001. Prólogo en La Cuadrícula en el desarrollo de la ciudad hispanoamericana, Guadalajara, México. Guadalajara: Universidad de Guadalajara, ITESO. 202.

5 Cabrales, Luis Felipe. 2006. "Divide y venderás: promoción inmobiliaria del barrio de Artesanos de Guadalajara, 1898-1908". Geografía histórica e historia del territorio vol. 10 Scripta Nova: revista electrónica de geografía y ciencias sociales.

6 Términos utilizados por Eduardo López Moreno en: López Moreno, Eduardo. 2001. La Cuadrícula en el desarrollo de la ciudad hispanoamericana, Guadalajara, México. Guadalajara: Universidad de Guadalajara, ITESO. 201. Para describir el sistema en damero o cuadrícula, empleado por los españoles dentro del sistema fundacional de las ciudades novohispanas.
7 De la Torre, Ernesto. 2013."Época colonial. Siglos XVI y XVII", en Historia documental de México. Volumen I, ed. por Miguel León Portilla. México: UNAM. 473, 474.

8 Descripción de la tipología de las casas en esquina de la Guadalajara de antaño en: Villaseñor y Villaseñor, Ramiro. 1987. Las calles históricas de Guadalajara Tomo II. Guadalajara: Gobierno de Jalisco. 44.

9 Vázquez, Daniel. 2001. Prólogo en La Cuadrícula en el desarrollo de la ciudad hispanoamericana, Guadalajara, México. Guadalajara: Universidad de Guadalajara, ITESO. 202.

10 Muriá, José María. 1981. Historia de Jalisco. Tomo II. De finales del siglo XVII a la caída del federalismo. Guadalajara: El Colegio de Jalisco. 260.

11 Ricard Morant Marco y Arantxa Martín López. 2013. "El lenguaje de los balcones". Revista Signa 22: 497-513. Universitat de València.

12 Gallo Pérez, Celia Guadalupe. 2005. Una visión de la Guadalajara de fines del siglo XIX y principios del actual. Guadalajara: Gobierno del Estado de Jalisco. 42.

13 Gallo Pérez, Celia Guadalupe. 2005. Una visión de la Guadalajara de fines del siglo XIX y principios del actual. Guadalajara: Gobierno del Estado de Jalisco. 42.

14 Valerio Ulloa, Sergio. 2006. "Empresas, tranvías y alumbrado público. La compañía hidroeléctrica e irrigadora de Chapala". En Poder público y poder privado. Gobiernos, empresarios y empresas 1880-1980, 244. México: UNAM.

15 Uribe Topete, Francisco Javier. 1992. Los transportes de los tapatíos. En Capítulos de historia de la ciudad de Guadalajara Tomo 1. 186-187. Guadalajara: Ayuntamiento de Guadalajara.

16 Villaseñor y Villaseñor, Ramiro. 1987. Las calles históricas de Guadalajara Tomo II. Guadalajara: Gobierno de Jalisco. 180.

17Segawa, Hugo. 2010. La sociedad de las antologías, Cultura arquitectónica de la modernidad mexicana, Antología de textos 1922-1963. México: UNAM. 12.

18 González Huezo, Arabella. 2005. Guía arquitectónica Zona Metropolitana 
de Guadalajara. Guadalajara: Secretaría de Cultura del Gobierno del estado de Jalisco. 167.

19 De Solá Morales, Manuel. 2002. Ciudades y esquinas urbanas. Barcelona: Los monográficos de B.MM. 133.

\section{Referencias}

Cabrales, Luis Felipe. 2006. "Divide y venderás: promoción inmobiliaria del barrio de Artesanos de Guadalajara, 1898-1908". Geografia histórica e historia del territorio vol. 10 Scripta Nova: revista electrónica de geografía y ciencias sociales.

De Solá Morales, Manuel. 2002. Ciudades y esquinas urbanas. Barcelona: Los monográficos de B.MM.

Gallo Pérez, Celia Guadalupe. 2005. Una visión de la Guadalajara de fines del siglo XIX y principios del actual. Guadalajara: Gobierno del Estado de Jalisco.

González Huezo, Arabella. 2005. Guía arquitectónica Zona Metropolitana de Guadalajara. Guadalajara: Secretaría de Cultura del Gobierno del estado de Jalisco.

León Portilla, Miguel. 2013. Historia documental de México. Volumen I. México: UNAM.

López Moreno, Eduardo. 2001. La Cuadrícula en el desarrollo de la ciudad hispanoamericana, Guadalajara, México. Guadalajara: UdeG-ITESO.

Lynch, Kevin. 2015. La imagen de la ciudad. Barcelona: Gustavo Gili.

Morris, A.E.J. 2015. Historia de la forma urbana. Barcelona: Gustavo Gili.

Muriá, José María. 1981. Historia de Jalisco. Tomo II. De finales del siglo XVII a la caída del federalismo. Guadalajara: El Colegio de Jalisco.

Rossi, Aldo. 2015. La arquitectura de la ciudad. Barcelona: Gustavo Gili.

Segawa, Hugo. 2010. La sociedad de las antologías, Cultura arquitectónica de la modernidad mexicana, Antología de textos 1922-1963. México: UNAM.

Uribe Topete, Francisco Javier. 1992. Capítulos de historia de la ciudad de Guadalajara Tomo 1. Guadalajara: Ayuntamiento de
Guadalajara.

Valerio Ulloa, Sergio. 2006. Poder público y poder privado. Gobiernos, empresarios y empresas 1880-1980. México: UNAM.

Villaseñor y Villaseñor, Ramiro. 1987. Las calles históricas de Guadalajara Tomo II. Guadalajara: Gobierno de Jalisco.

Weber, Max. 1987. La ciudad. Madrid: Las ediciones de la piqueta. 